\title{
A new dataset on decision-making in the European Union before and after the 2004 and 2007 enlargements (DEUII)
}

\author{
Robert Thomson, Javier Arregui, Dirk Leuffen, \\ Rory Costello, James Cross, Robin Hertz and \\ Thomas Jensen
}

\begin{abstract}
We present a new dataset on decision-making in the European Union (DEUII) that revises and expands a previous dataset. Researchers are using this new dataset to address a range of research questions regarding the inputs, processes and outputs of the EU's legislative system. The dataset contains information on 331 controversial issues raised by 125 legislative proposals that were introduced between 1996 and 2008. For each of these controversial issues, the dataset identifies the policy alternative favoured most by each of the main political actors: the European Commission; the European Parliament; and each of the member states' representatives in the Council of Ministers. This information was assembled during 349 semi-structured interviews with key informants. This article describes the dataset and identifies its relevance to several research agendas in EU studies.
\end{abstract}

KEY WORDS European Union; legislative politics; policy positions; dataset

\section{INTRODUCTION}

Scientific research on any political system is strengthened by systematic information on political actors' policy positions and decision outcomes on controversial issues. With information on what the main actors wanted and how controversies were resolved, political scientists can answer a range of questions regarding the inputs, processes and outputs of the political systems they study. The dataset we describe contains such information for legislative decisionmaking in the European Union (EU). It includes 125 important legislative proposals, such as the 1998 savings tax proposal, the 2004 working time proposal and the 2005 proposal to liberalize postal services. The new dataset gives information on the policy positions of the European Commission, the European Parliament and member states' representatives in the Council of Ministers. For a subset of the selected proposals, the dataset also gives information on 
the policy positions of national and party groups in the European Parliament (EP). The next section describes the dataset and illustrates the information it contains with an example. We then address some criticisms that have been raised in response to these data. The final section outlines several research questions that are being and could be addressed using the dataset.

\section{THE DATASET}

This section gives a summary description of the dataset based on two previous and more extensive descriptions of the research design (Thomson 2011: ch. 2; Thomson and Stokman 2006). The new dataset we present includes information from a previous project on decision-making in the EU-15 (Thomson et al. 2006). We revised the dataset from this previous project and updated it with cases from the enlarged EU in a way that ensures the new information is comparable. ${ }^{1}$ The procedure used to assemble this dataset is an established one (e.g., Bueno de Mesquita 2009a; Bueno de Mesquita and Stokman 1994). It applies the spatial model of politics to specific controversies with the help of interviews with key informants.

Figure 1 illustrates the information contained in the dataset with the legislative proposal on emission allowances in the aviation sector (COD/2006/304). Each legislative proposal raised one or more controversial issues that are represented as one or more policy scales that map out the policy alternatives considered. This proposal sought to tackle climate change by including the aviation sector in the EU's emissions trading scheme. The first controversial issue concerned the calculation of the carbon dioxide $\left(\mathrm{CO}_{2}\right)$ pollution allowances that should be given to the airline industry. On one side of this debate were the actors that favoured a relatively low quantity of allowances, which would drive up the cost of polluting; these actors consisted of the Commission, EP and old EU-15 member states, although there were some differences within this latter group. On the other side of the debate were the 12 new member states; these actors favoured a relatively high quantity of allowances, which would permit the aviation industry to pollute more. The second controversy concerned the auctioning of carbon credits; the issue was about what proportion of these credits the aviation industry should be allowed to auction. Again, the new member states took the same position, which was that there should be no auctioning. They argued that this would impose unacceptable costs on the aviation industry. The other actors favoured auctioning, but to different degrees. The Commission and most old member states took a conservative position that a small proportion of the credits should be auctioned. The EP together with Ireland and Sweden took the most radical position, arguing that the industry should be allowed to auction a far larger amount of credits. The EP's first opinion stated that 25 per cent of credits should be auctioned in 2011 and that this percentage should be increased to the level in other sectors in subsequent years. Note that the placement of the policy alternatives on these scales are not determined simply by the units referred to (in this case 
What are the positions of the actors regarding the total $\mathrm{CO} 2$ emission allowances for the aviation industry?

Low level of regulation

igh level of regulation

BU, CY, CZ, EE, HU, LV, LT, MT,

PL, RO, SI, SK

\begin{tabular}{|l|r|r|r|r|}
\hline \multicolumn{3}{|c|}{ UK } & EP \\
\hline $\begin{array}{l}\text { Position 0: Based } \\
\text { on an emissions } \\
\text { level closer to the } \\
\text { start date of the } \\
\text { regualtion }\end{array}$ & $\begin{array}{rrrr}70: 95 \% \text { of the } \\
2005-07\end{array}$ & $\begin{array}{r}90: \text { Annual } \\
\text { average of } \\
\text { annual average } \\
\text { emissions }\end{array}$ & $\begin{array}{r}\text { Position } \\
\text { emissions. } \\
\text { Outcome }\end{array}$ & $\begin{array}{r}100 \\
\text { reference } \\
\text { year }\end{array}$ \\
\hline
\end{tabular}

What are the positions of the actors regarding the auctioning of carbon credits?

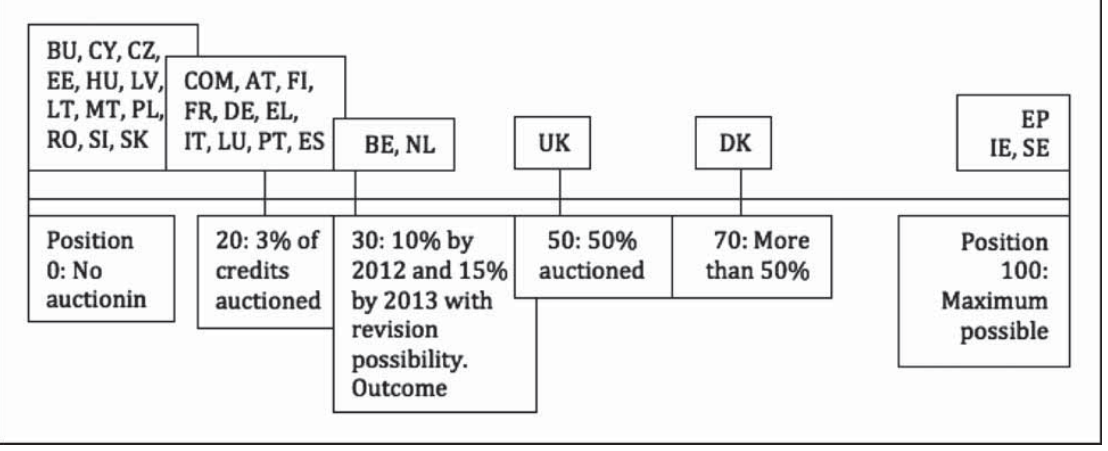

Figure 1 The main controversies raised by the proposed directive on emission allowances in the aviation sector

Notes: Proposal COD/2006/304.

COM: Commission; EP: European Parliament; AT: Austria; BE: Belgium; BU: Bulgaria; CY: Cyprus; CZ: The Czech Republic; DK: Denmark; EE: Estonia; FI: Finland: FR: France; DE: Germany; EL: Greece; HU: Hungary; IE: Ireland; IT: Italy; LV: Latvia; LT: Lithuania; LU: Luxembourg; MT: Malta; NL: The Netherlands; PL: Poland; PT: Portugal; RO: Romania; SI: Slovenia; SK: Slovakia; ES: Spain; SE: Sweden; UK: The United Kingdom.

percentages), but rather by key informants' judgements of the political distances between the alternatives.

Political actors often differ from each other in terms of the importance they attach to issues. This means that one actor may invest far more time and effort than other actors in attempting to influence the decision outcome on an issue. It also means that actors may differ in their perception of the size of the difference between two policy options. For example, for the Commission and most member states the quantity of allowances was more important than the auctioning of carbon credits. However, for the EP, Ireland and Sweden, our data 
indicate that the auctioning of carbon credits was at least as important as the quantity of allowances. We will return to the operationalization of issue salience below.

\section{Selecting legislative proposals}

A total of 125 legislative proposals were selected for study, 69 from the EU-15 time period and 56 from the post-2004 time period. The documentation that accompanies the dataset contains a complete list of these legislative proposals. Thomson et al. (2006) formulated the selection criteria for a study of decision-making in the EU-15, and we extended these criteria to the enlarged EU.

Three criteria were used to select the legislative proposals: procedure; time period; and political importance involving controversy. The first of these criteria, procedure, was that the proposals had to be subject to either the co-decision or the consultation procedure. Table 1 summarizes the selected legislative proposals by the procedure to which they were subject. The selection does not include proposals that were introduced under one procedure and changed to another procedure after the Treaty of Amsterdam came into effect on 1 May 1999.

The second selection criterion concerns the time period. For the EU-15 study, proposals that were introduced or pending between January 1999 and December 2000 were selected for study. For the post-2004 study, we selected proposals that were first discussed in the Council and EP after the accession of the 10 member states in 2004 . The post-2004 study includes proposals that were introduced up to July 2008.

Table 1 Distribution of selected proposals and issues by decision-making procedures

\begin{tabular}{cllcc}
\hline Time period & $\begin{array}{c}\text { EP } \\
\text { involvement }\end{array}$ & $\begin{array}{c}\text { Council } \\
\text { voting rule }\end{array}$ & $\begin{array}{c}\text { Proposals selected } \\
\text { by researchers }\end{array}$ & $\begin{array}{c}\text { Issues identified } \\
\text { with experts }\end{array}$ \\
\hline $\begin{array}{c}\text { EU-15 } \\
\text { (1999- }\end{array}$ & Consultation & QMV & $22(22)$ & $55(55)$ \\
$2000)$ & & Unanimity & $19(19)$ & $43(43)$ \\
& Co-decision & QMV & $22(22)$ & $59(58)$ \\
& & Unanimity & $6(6)$ & $16(16)$ \\
Post-2004 & Consultation & QMV & $16(16)$ & $41(41)$ \\
& & Unanimity & $3(3)$ & $9(9)$ \\
& Co-decision & QMV & $36(35)$ & $104(102)$ \\
& & Unanimity & $1(0)$ & $4(0)$ \\
Total & & & $125(123)$ & $331(324)$ \\
\hline
\end{tabular}

Note: In parentheses are the numbers of proposals and issues with final decision outcomes. 
The third selection criterion is political importance involving controversy. For the EU-15 period, each proposal, which could be a proposed directive, regulation or decision, was mentioned in a report of five lines or longer in Agence Europe, a daily news service devoted to EU affairs read mostly by EU practitioners. In addition, the experts we interviewed had to identify at least one substantive disagreement between at least some of the actors for the proposal in question to be included in the selection. We also asked the experts to name other proposals they were working on that met our selection criteria of relevant procedures and political importance and included these if they were not already in the selection. These procedures led to a relatively large number of proposals that were initially selected, but then found to be uncontroversial when the researchers consulted the experts. Consequently, for the post-2004 cases, two changes were made. First, decisions were excluded because most of the decisions included in the initial selection proved to be uncontroversial. Decisions are legislative acts directed toward specific member states or legal entities. Second, we tightened the news report coverage to require that a proposal be mentioned in reports of at least five lines in both Agence Europe and European Voice. European Voice is a weekly newspaper with a somewhat broader and less specialized readership than Agence Europe. The consequence of these changes is that the post2004 cases are confined to a set of proposals with a somewhat higher profile than the EU-15 selection.

Given the policy areas in which legislative activity is most intense in the EU, certain areas feature prominently. The selection contains a high proportion of legislative proposals from the areas of agriculture (26), internal market (18), Justice and Home Affairs (11) and fisheries (14). However, many other policy areas are present too, which allows us to examine the extent to which patterns in inputs, processes and outputs can be generalized across different policy areas.

\section{Interviewing key informants}

We and our colleagues held 349 semi-structured interviews with experts to gather information on the controversies raised by the legislative proposals selected (Table 2). The interviews lasted on average 78 minutes. During these interviews, experts gave information on the actors' policy positions on the controversial issues and the levels of importance the actors attached to the issues.

We relied on a small number of experts for each case, who were interviewed face-to-face and required to justify the information they provided substantively. This approach is appropriate in the present context because we focus on controversies raised by each of the selected legislative proposals. This means we need detailed discussions with experts to find out what exactly was controversial about these proposals. Moreover, given that decision-making in the Council of Ministers is not open to the public, the information we require is often of a sensitive nature. Few experts would be willing to divulge this information in a standardized questionnaire to researchers whom they have not met personally. ${ }^{2}$ 
Table 2 Interviews held to obtain information on the selected legislative proposals

\begin{tabular}{lccr}
\hline & EU-15 & Post-2004 & Total \\
\hline Numbers of interviews by institutional affiliation of experts & & & \\
Commission & 19 & 28 & 47 \\
European Parliament & 2 & 43 & 45 \\
Permanent representations of member states & 78 & 158 & 236 \\
Council Secretariat & 6 & 3 & 9 \\
Interest groups & 12 & 0 & 12 \\
Total & 117 & 232 & 349 \\
Duration of interviews in minutes & & & \\
Average & 103 & 65 & 78 \\
Standard deviation & 57 & 22 & 42 \\
\hline
\end{tabular}

This approach allows interviewers to assess the expertise of interviewees and the amount of effort interviewees devote to providing estimates. Throughout the semi-structured interviews, interviewers asked respondents to justify the information they gave. The guiding questions for these justifications were 'why did each of the actors favour the alternatives they did?' and 'why did the actors prioritize the issues as they did?' (Thomson and Stokman 2006: 32). Respondents' answers to these questions and the knowledge they displayed of the proposal in question were used to gauge their expertise and the credibility of their estimates. The numerical representations of actors' positions are not averages of the estimates provided by different experts. When necessary, researchers made a judgement about which sets of estimates to include based on respondents' answers. In the post-2004 period, we found that experts were sometimes unsure of or unable to provide estimates for all of the actors. In such cases we combined estimates from different experts. When doing so, we presented experts with previously collected information, and asked them to comment on this information and fill in the missing pieces.

The experts were affiliated with different institutions: generally the European Commission; one of the member states' permanent representations; or the European Parliament. The individuals in the Commission were usually the officials responsible for drafting the legislative proposals. These individuals also monitored closely the discussions that took place in the Council and EP. The officials from member states' representations were desk officers responsible for representing their states in the Council discussions. For part of the post-2004 study, data were gathered on the policy positions of the party and where relevant national groups in the EP, and a larger number of experts from the EP were interviewed accordingly.

\section{Reconstructing controversial issues with experts}

The first part of each interview focussed on specifying the issues as policy scales, such as those depicted in Figure 1. The experts were first asked to identify the 
main disagreements or controversies raised by the legislative proposal in question. The specification of the issues is closely connected with the estimates of actors' policy positions, since the policy positions are represented on the issues. For each issue, the expert was first asked to identify the actors that favoured the most extreme policy alternatives. These policy alternatives then defined the endpoints of the issue continuum used to represent this controversy, which for convenience we gave a range of $0-100$.

The following criteria are important when specifying issues. The issues should:

- represent the main points of controversy;

- contain positions that define the substance of the alternative decision outcomes; and

- be unidimensional so that actors' preferences for the policy alternatives on each issue can be represented with single-peaked preference functions (Thomson and Stokman 2006: 35).

The first criterion emphasizes that the issue specifications are stylized representations; they are not intended to capture all of the nuances and detailed points of discussion. We did not impose a limit on the number of issues specified, but experts generally found two or three issues to be sufficient. The average number of issues used to represent the controversies in each proposal is 2.65, ranging from one to six (s.d. $=1.28, \mathrm{n}=125$; see also Table 1 ). There is obviously some room for judgement by researchers and experts on how many issues to formulate, taking into account the uniqueness of each case. We generally excluded points that were of relevance to only a few actors. The second criterion implies that the points on the policy scales should be defined in terms of the substantive decision outcomes considered during the decision-making process. In general, whenever placing an actor at a point on a policy scale, that position should be defined in terms of the substance of the decision outcome favoured by that actor. However, some actors' positions are inherently ambiguous. Occasionally, experts placed an actor between two substantively defined points on the scale, indicating that this actor was 'in between' these two positions.

The third criterion means that actors are assumed to derive most benefit or utility from the decision outcome that corresponds to their positions on the policy scales. Decision outcomes located further from actors' positions are valued less by those actors. In addition, the distances between the positions should reflect the political distances between the policy alternatives.

Given the range of policy areas and proposals included in the selection, the issues differ considerably from each other. For instance, some issues contain alternatives that involve different levels of harmonization of national arrangements, while others do not. Another difference between the issues concerns the number of policy alternatives on offer. Some issues contain a scale of alternative policies with one or more possible compromise outcomes between the 
extremes; others contain only two policy alternatives, and are referred to as 'dichotomous' issues. A total of 61 of the 331 issues are dichotomous.

\section{Expert judgements of actors and their policy positions}

For each issue, the experts were asked to indicate the policy alternative initially favoured by each stakeholder after the introduction of the proposal before the Council formulated its common position' (Thomson and Stokman 2006: 36; emphasis original). When making judgements about actors' positions, experts relied mainly on the stances taken by those actors when the legislative proposal was introduced, or as soon as the actors took a stance after the introduction. Therefore, the information contained in the dataset examined here reflects actors' behaviour, in the form of statements made by representatives of those actors, rather than the actors' hidden preferences. A small experiment with different question wordings was held at the start of the research project. After collecting the positional information using the above wording, two interviewers asked 15 experts whether they could distinguish between the actors' real preferences and the policy positions they expressed at the outset. While the respondents recognized the theoretical significance of this distinction, none were able to translate this distinction systematically into different scale positions for each of the actors.

The distinction between actors' stated positions and hidden preferences is central to many theories in political science. Bueno de Mesquita (2004: 1301) noted that the question used in the semi-structured interviews was likely to elicit information on actors' revealed or strategic positions; information that is well-suited to a certain class of bargaining models. Many political scientists hold the view that since actors' real preferences are private to themselves, by definition preferences cannot be measured (ibid.; see also Benoit and Laver 2006: ch. 1). Nonetheless, the positions reported do contain information that reflects actors' underlying interests. The aviation emissions case (Figure 1) illustrates this, since actors' positions largely reflect their economic interests in this sector. Thomson (2011: ch. 6) addresses this question more systematically, by examining the extent to which similarities in member states' positions can be explained by the extent to which they share similar underlying economic and political attributes. To some extent they can, which implies that the positional data also reflect the underlying structural conditions that inform actors' preferences. Nonetheless, since preferences are not directly observable, we cannot dismiss the possibility that actors' stated positions differ from their preferences in systematic ways.

On any given controversial issue, it is common that a minority of actors do not have policy positions. ${ }^{3}$ Land-locked countries, for instance, rarely have positions on fisheries issues. One view, expressed by Arregui and Thomson (2009), is that indifference is a fundamental feature of the decision-making process and generally reflects actors' underlying interests. They show that there is a strong positive correlation between member states' size and the percentages of issues 
on which they take positions. They argue that large states, which have a broader range of interests, are bound to take positions on more issues than small states, which are affected by fewer issues. It is possible that key informants are simply less knowledgeable regarding small states' positions. However, on the issues on which we would expect particular small states to take positions, they did. Another view on actors without positions is that they are hiding these positions for strategic reasons; they are 'missing data' rather than 'indifferent' (König et al. 2005). This certainly happens too; some state representatives may remain quiet in the negotiations, allowing other states to make the case for them.

Experts gave information on the policy positions of the Commission, member states and EP, each of which was treated as a unitary actor. This is a simplifying assumption, since each of these actors is in fact a complex composite of a large number of individuals and competing factions. Nonetheless, if any of these actors are to participate in the European-level decision-making process, they must take a single position. The dataset disaggregates the Council by identifying the positions of the member states, but treats the Commission and EP for the most part as unitary actors. Decision-making within the EP is for the most part outside our focus. However, the dataset also contains a unique set of information on the positions of the party groups in the EP on a subset of the legislative proposals (Costello 2009); 16 of the post-2004 selection.

The experts also identified the 'reference point' for each issue, whenever possible. This is the decision outcome that would occur if the legislative proposal were not adopted: in other words, the decision outcome in the event of failure to agree. The reference point could not be measured for some issues. On some of the issues, the decision outcome in the event of disagreement referred to several different points on the scale. This may be the case, for instance, when states favour an EU regulation in line with their own national regulations. Failure to agree would then mean the continuation of different regulations in different member states. On some other issues, the issues are defined in such a way that they presuppose some kind of agreement. For example, the first issue in the aviation emissions case (Figure 1) presupposes that there is some agreement on the introduction of emission allowances, and the question is about the quantity to introduce. When the reference point could not be measured, we left this value blank rather than impose an arbitrary value.

\section{Expert judgements of issue salience}

Experts estimated the level of importance that each actor attached to each of the controversial issues. We refer to this as actors' issue salience. Issue salience reflects the intensity of actors' policy positions. A high level of salience is what turns a potential to influence into actual influence, because an actor with a high level of salience will put a high proportion of its potential to influence other actors and the decision outcome into effect. Actors may differ from each other in the level of the salience they attach to a given issue. In addition, any given actor may attach different levels of salience to two or more 
controversial issues. Issue salience is a key concept in models of political exchange and logrolling, in which actors make concessions on some issues in return for concessions from others on other issues (e.g., Coleman 1972).

Experts estimated the level of salience that each actor attached to each issue on a scale of 0 to 100 . The scale was introduced as follows.

Stakeholders differ from each other in the salience or importance they attach to issues. For example, a particular issue may be of great importance to one stakeholder but only marginal to another. Please estimate the salience each stakeholder attaches to each issue on a scale from 0 to 100. A score of 100 indicates that an issue is of the highest importance to a stakeholder, while a score of zero indicates that the issue is of no importance whatsoever to a stakeholder. A score of 50 indicates that the issue has an average level of priority for the stakeholder concerned, and that it is willing to use arguments but not power politics to convince opponents. Note that it is possible for a stakeholder to attach a high level of salience to an issue on which it takes a moderate position, and a low level of salience to an issue on which it takes an extreme position.

When obtaining experts' estimates of the salience of each issue to different actors, extensive comparisons were made both between the scores of different actors on the same issues and between the scores of the same actors on different issues. Interviewers often found it useful to ask the expert to first identify the actor with the highest salience score on any of the issues raised by the proposal, and then to make the other estimates relative to this benchmark. Interviewers asked experts to give reasons for their estimates throughout the interview. The $0-100$ salience scale has proven to be a useful heuristic for obtaining expert judgements on issue salience. In practice, experts use units of $10(50,60,70$, etc. $)$ and occasionally five $(50,55,65$, etc. $)$.

\section{Validity and reliability tests}

Thomson (2006) assessed the validity of the expert judgements by comparing expert judgements with information from documentation on Council decision-making on two cases: the directive on the manufacturing and sale of tobacco products $(\mathrm{COD} / 1999 / 244)$; and the directive on resale rights for artists (COD/1996/085). The documents contained uncensored drafts of the legislative texts that detailed member states' objections to articles within these proposed laws. The comparison of the expert judgements and documents revealed that the experts' issues were indeed the main controversies. For both legislative proposals, he compared the controversial articles from the documents that related to the experts' issues with the controversial articles from the documents that did not relate to the experts' issues. The documents showed that more member states took positions on the related articles than the unrelated ones. In addition, the related articles took longer to resolve and were discussed at higher levels of the Council's hierarchy. The comparison of documents with 
expert judgements also supported the validity of the experts' judgements of actors' policy positions. For the tobacco products directive, there was a high level of agreement between experts' judgements of states' positions and the information from documents; 48 of 53 positions matched perfectly. On the resale rights directive, only 18 of the 57 positions that could be compared matched. This lower level of agreement showed the limitation of the documents as a source of evidence. On the basis of a qualitative inspection, it was clear that the positions in the documents referred to states' responses to a compromise proposal during the course of the negotiations, not to the policy positions they initially favoured.

Both Thomson (2006) and König et al. (2007) assessed the reliability of the expert judgements by comparing the judgements of different experts with each other, both with satisfactory results. König et al. (2007: 294) examined the point location of 39 policy positions from seven of the issues included in the present study that were the subject of negotiation between the Council and the EP in conciliation committees. They compared the estimates of the experts used for the present study with estimates from experts in the EP: either rapporteurs or their legislative assistants. They found that 35 of the 39 estimates matched perfectly or almost perfectly.

\section{CRITICISMS OF THE DATASET}

In this section we address two criticisms that have been directed at this dataset. These criticisms are useful in that they direct our attention to the limitations of the dataset; like any dataset, it is relevant to some research questions, but not to others. ${ }^{4}$

The first criticism is that the dataset is biased by only including controversial legislative proposals. In response, we first point out that there is considerable variation in the levels of controversy surrounding the 125 legislative proposals included in the study. Some proposals raised considerable controversy, such as the savings tax and payment services directives. Other proposals may seem rather technical, such as a proposal to standardize requirements for transporting gas bottles. Therefore, this concern should not be taken to mean that the dataset includes only highly controversial cases.

This first criticism implies that the dataset would have been stronger if it had included uncontroversial proposals. However, cases that are uncontroversial are simply not relevant to the questions for which we designed this dataset. We are concerned with controversies in the EU and how these are resolved. For instance many of our analyses focus on the ways in which actors' policy positions are transformed into decision outcomes (e.g., Thomson et al. 2006). There are fundamentally different theories of how this transformation takes place. These different theories do not, however, generate different expectations of decision outcomes on uncontroversial issues. According to all models, if all of the relevant actors have the same policy position, that position will also be the decision outcome. Therefore, including uncontroversial issues would not bring 
information that would be useful in terms of testing alternative explanations. Obviously, the dataset is of little relevance to researchers whose primary interest lies in the question of how the EU decides on uncontroversial issues.

Another criticism is that controversial issues contained in the dataset refer to different matters and therefore cannot be compared, at least not in some ways. For example, some issues refer to levels of subsidy for particular EU programmes, while other issues refer to the strength of regulations regarding certain products or services. The difference between 0 and 100 on one policy scale may matter a lot less in terms of substantive policy difference than the same distance on another policy scale, even within the same policy area. According to this criticism, such differences mean that any comparison across issues is inappropriate.

The first response to this criticism is that the controversial issues are comparable in the sense that they map out the range of the bargaining space, i.e., the most different policy positions favoured by any two actors regarding the issue in question. Many of the analyses for which this dataset is used make no claims about the substance of the policy positions taken by the actors in question. Such analyses refer to information on political distances among actors' positions, not to the contents of the positions taken. For example, some of the analyses of the Commission's positions in relation to member states' positions show there is a bias whereby the Commission's policy positions are systematically closer to the positions of the home member state of the responsible Commissioner (Thomson 2011: ch. 4). This finding does not specify the content of the issues on which such biases occur. There is an important distinction between analyses that focus on political differences and analyses that focus on substantive policy differences. At least some variants of this criticism fail to recognize this important distinction.

The second response to this criticism regarding comparability is that certain subsets of issues are comparable in that they relate to similar policy themes. Using the qualitative information available on each of the controversial issues, it is possible to categorize the issues into thematically related groups. Some issues are about subsidy levels, other issues are about choices between free market and regulatory solutions to policy questions, and other issues are about levels of harmonization. We coded these issues consistently so that policy positions with higher values on the policy scales involve higher levels of subsidy, stronger regulation or more harmonization, where relevant. Using this information, it is possible to detect patterns whereby certain actors consistently call for higher subsidies (or stronger regulation or harmonization) when these types of issues arise. We should of course be mindful that actors' policy positions on each of these issues differ, depending on the substance of the detailed issue at stake. For example, a 'high subsidy' position may mean $€ 10 \mathrm{~m}$ on for one policy programme and $€ 100 \mathrm{~m}$ on another. However, this reminder does not detract from the inferences that can be drawn regarding the existence of patterns in actors' policy positions using the dataset. 
While we disagree with the assertion that all comparisons across issues are inappropriate, we recognize that there are limits to cross-issue comparisons. As the preceding discussion suggests, it would not be appropriate to assert that there was a larger substantive difference of opinion between two actors regarding a first issue than a second issue, because the distance between their positions was larger on the first issue than on the second issue. It may also be appropriate to use the data at an ordinal level for some research questions.

\section{USES}

Previous and ongoing studies that use this dataset or earlier versions of it demonstrate its relevance to a broad range of research questions regarding the inputs, processes and outputs of the EU's legislative system. We mention some of the main research questions to which the dataset is relevant and identify some questions that could be developed further. Since the dataset includes cases from before and after the historic 2004 and 2007 enlargements, these questions can be placed in the broader context of the impact of enlargement on the EU's political system (e.g., Thomson 2011; Hertz and Leuffen 2011). Future expansion of the dataset would create a resource with which to examine the impact of the new decision-making rules brought in by the Lisbon Treaty.

Regarding the inputs into the legislative system, previous research has used this dataset or earlier versions of it to examine the prevalence and type of patterns in the policy positions of different actors (e.g., Thomson 2009; Zimmer et al. 2005). The prevalence of patterns in the alignments of actors' policy positions is a highly pertinent question for political scientists. If member states are often divided along the lines of economic prosperity, as Zimmer et al. contend, this is potentially divisive. However, if there is little structure to actors' positions, as Thomson (2009) argues is the case, then such cross-cutting cleavages support a sense of solidarity in the presence of diversity in line with pluralist democratic theory (Dahl 1989: 251-4). Related research has also used the dataset to examine the impact of the characteristics of key actors, notably Commissioners and rapporteurs, in influencing the policy positions taken by the Commission and the EP (Costello and Thomson 2010; Thomson 2008). The research on the Commission has tested theories that explain the Commission's policy positions with reference to institutional, national and party political factors (e.g., Egeberg 2006; Hooghe 1999; Hug 2003).

There is scope for further inquiry into the causes of actors' policy positions using this dataset. With respect to member states' positions, existing studies have quantified the amount of structure and described and interpreted the patterns that are there. However, we have only begun to examine the impact of specific sectoral structural factors on variation in member states' positions (see Thomson [2011: ch, 6] for a first step in this direction). While existing research shows that the general ideological orientation of national governments is weakly, if at all, related to member states' policy positions at the EU level, this does not imply that national party politics is irrelevant to the distribution 
of policy positions in the Council. It may be the case that the ideological orientations of the relevant national ministers play a more decisive role, depending on the strength of inter-ministerial co-ordination mechanisms at the national level. With respect to the Commission's policy positions, future research could expand this dataset to consider the impact of interest groups during the consultations held by the Commission prior to the formulation of the legislative proposal, thereby expanding the scope of the dataset to the agenda-setting stage.

The design of the dataset was originally intended to test models of the process through which actors' policy positions are transformed into decision outcomes (Bueno de Mesquita and Stokman 1994; Thomson et al. 2006). These models encapsulate different views on the nature of the decision-making process. Some models define the main characteristics of the process by various forms of informal bargaining among actors, while other models define the process in terms of the formal rules of decision-making (e.g., Crombez 1996; Steunenberg 1994; Tsebelis 1994). One fairly robust finding from previous research is that a particular variant of the Nash Bargaining Solution generates the most accurate predictions of decision outcomes (Achen 2006).

Future research might examine a broader range of models to add further nuance to our knowledge about the nature of the decision-making process. This research is well under way (e.g., Bueno de Mesquita 2009b; Dijkstra et al. 2008; Schneider et al. 2010). Although these studies are theoretically and empirically sophisticated, no model has yet convincingly and significantly improved on the predictive accuracy of the Nash Bargaining Solution to predict the outcomes of a broad range of EU decisions. There are other, perhaps more fruitful ways of testing models than gauging the accuracy of their predictions of decision outcomes. In future research, more attention could be given to examining models' testable predictions of shifts in actors' policy positions, their behaviour at the voting stage, and the duration of decision-making. Many of the models could be used to derive propositions about variation in these key features of decision-making processes.

Regarding the outputs of the legislative system, the dataset has been used to test explanations of what has been referred to as 'bargaining success', the congruence between actors' policy positions and decision outcomes (e.g., Aksoy 2010; Arregui and Thomson 2009; Bailer 2004). The main descriptive finding is that there are no stark differences among member states in this respect. So while there are often winners and losers with respect to the outcomes of specific decisions, this is not the case when a larger number of outcomes are considered. The most powerful explanation of variation in bargaining success is quite simply the extent to which an actor's policy position is close to an obvious compromise position. This raises the question of whether 'success', which implies some form of agency, is the most appropriate term. Other explanatory variables are also relevant, including member states' resources, coalition potential, and their occupation of the presidency of the Council of Ministers at certain times of the legislative process (e.g., Schalk et al. 2007; Warntjen 2008). 
The outputs of the EU's legislative system are implemented by the Commission and member states' national administrations. The dataset is relevant to testing theories that explain variation in implementation by referring to the policy positions of decision-makers and implementers. Decision outcomes vary in the extent to which they delegate discretionary powers to the Commission and/or member states during the implementation stage after the adoption of the legislative act. Some theories of delegation posit that polarization in decision-makers' policy positions and incongruence between decision-makers and implementers' policy positions affect the likelihood of delegation to various implementers (e.g., Bender and Meirowitz 2004; Epstein and O'Halloran 1999; Franchino 2007; Pollack 2003; Thomson and Torenvleid 2011), and this dataset offers the most direct way of testing these propositions in the EU presently available. Similarly, the dataset offers possibilities to test theories of compliance that posit effects of member states' incentives to deviate, defined by incongruence between member states' policy positions and the decision outcomes they have to implement. Previous research tested these propositions with mixed results (e.g., Falkner et al. 2005: 278; König and Luetgard, 2009: 187-8; Mbaye 2001: 263). These mixed results may be due to the fact that the measures of member states' incentives to deviate did not directly relate to the measures of compliance performance used in these studies. Some recent studies have used this dataset to explore these relationships more directly (e.g., Thomson et al. 2007; Zhelyazkova and Torenvlied 2009). A promising emerging line of inquiry links this dataset with qualitative indicators of compliance performance on specific issues to examine variation at a more detailed level of analysis (Zhelyazkova and Torenvlied 2011).

The abovementioned research questions relate to the positive analysis of how the EU's legislative system works. Positive analysis can and should also have implications for evaluating and improving a political system. In this respect, the dataset supports analyses that address at least some of the important claims made in the debate surrounding the EU's democratic deficit (e.g., Follesdal and Hix 2006; Hix 2008; Moravcsik 2008; Weiler et al. 1995). For instance, some of these claims centre on the power of the EU's unelected bureaucracy, the Commission, relative to the (in)directly elected Council and EP, while other claims refer to the power of the EP relative to the Council. The dataset supports analyses that address these claims with evidence. Reform proposals involve changes to formal rules or informal practices, and the effects and feasibility of some of these can be assessed using the information provided by this dataset. For example, Hix (2008: 90) calls for more structured competition across a range of issues so that citizens can identify 'the winners and losers of policy outcomes'. This could involve structured co-operation between groups of actors, including member states. Researchers could use the dataset to assess the feasibility of such co-operation by examining the similarities among actors' policy positions in different areas. Our evaluations of the EU's political system and the feasibility of various reform proposals change over time as the EU changes. While it has become commonplace to refer to the EU's 'constitutional 
equilibrium', the EU continues to change in response to enlargement, crises, and the gradual maturing of its institutions, notably the EP. By assembling information on decision-making in a comparable way over time, this dataset is a resource for charting continuity and change in the EU's legislative system.

Biographical notes: Robert Thomson is an associate professor at Trinity College Dublin. Javier Arregui is an associate professor at Pompeu Fabra University. Dirk Leuffen is a professor at the University of Konstanz. Rory Costello is a lecturer at the University of Limerick. James Cross is a postdoctoral fellow at the ETH Zurich. Robin Hertz was a Ph.D. researcher at ETH Zurich. Thomas Jensen is a Ph.D. researcher at ETH Zurich.

Address for correspondence: Robert Thomson, Department of Political Science, College Green, Trinity College, Dublin 2, Ireland. email: thomsor@tcd.ie

\section{ACKNOWLEDGEMENTS}

We thank those who participated in the EU-15 project on which our work builds: Christopher Achen; Stefanie Bailer; Vincent Boekhoorn; Madeleine Hosli; Thomas König; Antti Pajala; Gerald Schneider; Torsten Selck; Frans Stokman; Bernard Steunenberg; Adrian Van Deemen; and the late Mika Widgrén. We ask that researchers who use the dataset presented here cite Thomson et al. (2006) as well as the present article to acknowledge their important contribution. We thank Manuel Schmitz and Caroline Rosenthal for research assistance and the hundreds of policy-makers in Brussels whom we interviewed. The dataset and relevant documentation are available at http:// www.robertthomson.info/; http://www.upf.edu/dcpis/en/pdi/professorat/jam. html; and http://www.polver.uni-konstanz.de/leuffen/.

\section{NOTES}

1 We did not simply append the new data to the EU-15 data. We added observations regarding decision outcomes that were pending at the time of the previous study and corrected some errors we found in the previous dataset. A total of 56 issues that were in the first version of the DEU dataset, which consisted of 174 issues, were changed in some way. Most of these changes were small, such as changing the direction of the scales so that higher values represented more harmonization or regulation wherever possible. Full details of the changes are available in the documentation accompanying the dataset.

2 Since our respondents provided information about other actors' policy positions as well as their own, they may be referred to as 'proxy respondents'. This type of respondent is common in health research.

3 In the EU-15 period a maximum of 17 actors could have taken positions (the 15 member states plus the Commission and EP). On the 173 issues in the dataset from the EU-15 period, an average of 15.54 actors took positions. In the EU-25 
period, the average number of actors with positions was 20.80 (41 issues). In the EU-27 period, the average number of actors with positions was 23.18 (117 issues).

4 These criticisms were mostly encountered through informal sources, such as at conferences, or in anonymous reviews of papers that later became published articles, and thus are not listed in the references. We thank the colleagues who raised these points for their thoughtful engagement with the dataset.

\section{REFERENCES}

Achen, C.H. (2006) 'Evaluating political decision-making models', in R. Thomson, F.N. Stokman, C.H. Achen and T. König (eds), The European Union Decides, Cambridge: Cambridge University Press, pp. 264-98.

Aksoy, D. (2010) 'It takes a coalition: coalition potential and legislative decisionmaking', Legislative Studies Quarterly 35(4): 519-42.

Arregui, J. and Thomson, R. (2009) 'States' bargaining success in the European Union', Journal of European Public Policy 16: 655-76.

Bailer, S. (2004) 'Bargaining success in the European Union: the impact of exogenous and endogenous power resources', European Union Politics 5(1): 99-124.

Bendor, J. and Meirowitz, A. (2004) 'Spatial models of delegation', American Political Science Review 98: 293-310.

Benoit, K. and Laver, M. (2006) Party Policy in Modern Democracies, London: Routledge.

Bueno de Mesquita, B. (2004) 'Decision-making models, rigor and new puzzles', European Union Politics 5: 125-38.

Bueno de Mesquita, B. (2009a) Principles of International Politics, 4th edn, Washington, DC: CQ Press.

Bueno de Mesquita, B. (2009b). 'A new model for forecasting policy choices: preliminary tests', Paper presented at the annual meeting of the International Studies Association, New York, 15-18 February 2008.

Bueno de Mesquita, B. and Stokman, F.N. (eds) (1994) European Community Decision Making: Models, Applications and Comparisons, New Haven, CT: Yale University Press.

Coleman, J.S. (1972) 'Systems of social exchange', Journal of Mathematical Sociology 2: 145-63.

Costello, R. (2009) 'Bicameral politics in the European Union', Ph.D. thesis, Trinity College, Dublin.

Costello, R. and Thomson, R. (2010) 'The policy impact of leadership in committees: rapporteurs' influence on the European Parliament's opinions', European Union Politics 11(1): 1-26.

Crombez, C. (1996) 'Legislative procedures in the European Community', British Journal of Political Science 26: 199-228.

Dahl, R.A. (1989) Democracy and its Critics, New Haven, CT: Yale University Press.

Dijkstra, J., Van Assen, M.A.L.M. and Stokman, F.N. (2008) 'Outcomes of collective decisions with externalities predicted', Journal of Theoretical Politics 20(4): 415-41.

Egeberg, M. (2006) 'Executive politics as usual: role behaviour and conflict dimensions in the College of European Commissioners', Journal of European Public Policy 13(1): 1-15.

Epstein, D. and O'Halloran, S. (1999) Delegating Powers. A Transaction Cost Politics Approach to Policy Making under Separate Powers, Cambridge: Cambridge University Press.

Falkner, G., Treib, O., Hartlapp, M. and Leiber, S. (2005) Complying with Europe: EU Harmonisation and Soft Law in the Member States, Cambridge: Cambridge University Press. 
Follesdal, A. and Hix, S. (2006) 'Why there is a democratic deficit in the EU: a response to Majone and Moravcsik', Journal of Common Market Studies 44(3): 533-62.

Franchino, F. (2007) The Powers of the Union: Delegation in the EU, Cambridge: Cambridge University Press.

Hertz, R. and Leuffen, D. (2011) 'Group size and formalization. a comparison of european union decision-making before and after Eastern enlargement', Geopolitics, History and International Relations 3(1): 59-76.

Hix, S. (2008) What's Wrong with the European Union and How to Fix it, Cambridge: Polity Press.

Hooghe, L. (1999) 'Images of Europe: orientations to European integration among senior officials of the commission', British Journal of Political Science 29(2): 345-67.

Hug, S. (2003) 'Endogenous preferences and delegation in the European Union', Comparative Political Studies 26(1-2): 41-74.

König, T., Finke, D. and Daimer, S. (2005) 'Ignoring the non-ignorables? Missingness and missing positions', European Union Politics 6: 269-90.

König, T. and Luetgert, B. (2009) 'Troubles with transposition? Explaining trends in member-state notification and delayed transposition of EU directives', British Journal of Political Science 39: 163-94.

König, T., Lindburg, B., Lechner, S. and Pohlmeier, W. (2007) 'Bicameral conflict resolution in the European Union: an empirical analysis of conciliation committee bargains', British Journal of Political Science 37: 281-312.

Mbaye, H. (2001) 'Why national states comply with supranational law. Explaining implementation infringements in the European Union 1972-1993', European Union Politics 2(3): 259-81.

Moravcsik, A. (2008) 'The myth of Europe's democratic deficit', Intereconomics (November-December): 331-40.

Pollack, M.A. (2003) The Engines of European Integration: Delegation, Agency and Agenda Setting in the EU, Oxford: Oxford University Press.

Schalk, J., Torenvlied, R., Weesie, J. and Stokman, F.N. (2007) 'The power of the Presidency in EU Council decision-making', European Union Politics 8(2): 229-50.

Schneider, G., Finke, D. and Bailer, S. (2010) 'Bargaining power in the European Union: an evaluation of competing game-theoretic models', Political Studies 58: 85-103.

Steunenberg, B. (1994) 'Decision-making under different institutional arrangements: legislation by the European Community', Journal of Theoretical and Institutional Economics 150: 642-69.

Thomson, R. (2006) 'Comparison of expert judgements with each other and with information from Council documentation', in R. Thomson, F. N. Stokman, C. H. Achen and T. König (eds), The European Union Decides, Cambridge: Cambridge University Press, pp. 329-47.

Thomson, R. (2008) 'National actors in international organizations: the case of the European Commission', Comparative Political Studies 41: 169-92.

Thomson, R. (2009) 'Actor alignments in the European Union before and after enlargement', European Journal of Political Research 48: 756-81.

Thomson, R. (2011) Resolving Controversy in the European Union, Cambridge: Cambridge University Press.

Thomson, R. and Stokman, F.N. (2006) 'Research design: measuring actors' positions, saliences and capabilities', in R. Thomson, F.N. Stokman, C.H. Achen and T. König (eds), The European Union Decides, Cambridge: Cambridge University Press, pp. 25-53.

Thomson, R., Stokman, F.N., Achen, C.H. and König, T (eds) (2006) The European Union Decides, Cambridge: Cambridge University Press. 
Thomson, R. and Torenvlied, R. (2011) 'Information, commitment and consensus: a comparison of three perspectives on delegation in the European Union', British Journal of Political Science 41: 139-59.

Thomson, R., Torenvlied, R. and Arregui, J. (2007) 'The paradox of compliance: infringements and delays in transposing European Union directives', British Journal of Political Science 37: 685-709.

Tsebelis, G. (1994) 'The power of the European Parliament as a conditional agenda setter', American Political Science Review 88: 128-42.

Warntjen, A. (2008) 'The Council Presidency: power broker or burden? An empirical analysis', European Union Politics 9: 315-38.

Weiler, J.H.H., Haltern, U.R. and Mayer, F.C. (1995) 'European democracy and its critique', West European Politics 18(3): 4-39.

Zhelyazkova, A. and Torenvlied, R. (2009) 'The time-dependent effect of conflict in the Council on delays in the transposition of EU directives', European Union Politics 10: 35-62.

Zhelyazkova, A. and Torenvlied, R. (2011) 'The successful transposition of different provisions by member states: an application to the Framework Equality Directive', Journal of European Public Policy 18(5): 690-708.

Zimmer, C., Schneider, G. and Dobbins, M. (2005) 'The contested Council: conflict dimensions of an intergovernmental EU institution', Political Studies 53: 403-22. 